\title{
ANALISIS EFEKTIVITAS KEBIJAKAN DAN PROGRAM BADAN PENGENDALIAN DAMPAK LINGKUNGAN DAERAH (BAPEDALDA) KOTA BATAM TERHADAP PENINGKATAN PERSENTASE PELAKSANAAN AMDAL
}

\author{
Timbul Dompak, Riko Riyanda \\ Universitas Putera Batam \\ e-mail: dompaksibarani@gmail.com
}

\begin{abstract}
Prototype of Batam as an industrial city in Indonesia with a variety of large factories has impacts on the environment. For example, waste and air pollution. AMDAL (Environmental Impact Assessment) issue becomes an urgent issue for Batam government which involves the role of Bapedalda Batam. The data of Batam Bapedalda from 2011 to 2015 showed the improvement of AMDAL. This study aims atanalyzing the policies and programs of Batam Environmental Impact Management Agency (Bapedalda) to the increase of AMDAL percentage. Method of collecting datawas done by interview, observation and documentation. Technique of selecting informant was purposive sampling, data analysis technique was done by data reduction, data presentation and conclusion. For large-scale industrial areas such as Batamindo, Kabil, Panbil the implementation of AMDAL have been effective but for the coastal area is still less effective because of investor low awareness. There are three things to increase the percentage of AMDAL: (1) increasing the investor requirement of voluntary from company, (2) effort in socialization context, door to door service, (3) public awarenessby applying law enforcement.
\end{abstract}

Keywords: Effectiveness, Policy, Program, Environmental Impact Assessment (EIA)

\begin{abstract}
Abstrak
Prototipe Kota Batam sebagai kota industri di Indonesia mulai tumbuh berbagai pabrik-pabrik besar tetapi kondisi tersebut menimbulkan dampak terhadap permasalahan lingkungan. Misalnya, tumpukan sampah, limbah dan pencemaran air mengakibatkan perusakan lingkungan. Permasalahan AMDAL ini menjadi persoalan yang urgen bagi pemerintah Kota Batam dalam hal ini melibatkan peran institusi Bapedalda Batam. Gambaran data Dinas Bapedalda Kota Batam dari tahun 2011 sampai ke tahun 2015 angka persentasenya memperlihatkan peningkatan AMDAL. Penelitian ini bertujuan untuk menganalisis efektivitas kebijakan dan program Badan Pengendalian Dampak Lingkungan Daerah (Bapedalda) Kota Batam terhadap peningkatan persentase peningkatan AMDAL. Metode pengambilan data dilakukan dengan cara wawancara, observasi dan dokumentasi, teknik pemilihan informan dengan purposive sampling, teknik analisis data dilakukan dengan reduksi data, penyajian data dan penarikan kesimpulan. Efektifitas AMDAL di Kota Batam untuk kawasan industri yang berskala besar seperti Batamindo, Kabil, Panbil sudah efektif dalam pelaksanaan AMDALnya. hanya saja untuk kawasan daerah pantai memang masih kurang efektif sebab masih ditemukan kurangnya kesadaran dan sifat-sifat nakal oleh pengelola perusahan (investor). Terdapat 3 poin dalam peningkatan persentase AMDAL yaitu: (1) peningkatan kebutuhan investor dalam bentuk vouluntery dari perusahaan, (2) Usaha kita dalam konteks sosialisasi, pembinaan dalam bentuk dor to dor, (3) Penyadaran publik dengan melakukan law enforcement.
\end{abstract}

Kata Kunci : Efektivitas, Kebijakan, Program, AMDAL 


\section{PENDAHULUAN}

Pembangunan industri di Kota Batam merupakan bagian dari pembangunan nasional yang menjadikan keberadaan Batam sebagai daerah yang strategis. Kota Batam merupakan sebuah pulau yang terletak di jalur pelayaran Internasional. Masyarakat Kota Batam merupakan masyarakat heterogen yang terdiri dari beragam suku dan golongan. Batam akan segera menjadi Kawasan Ekonomi Khusus (KEK), saat ini pemerintah masih mempersiapkan berbagai proyek infrastruktur di kawasan tersebut (Angel Purwanti, 2016).

Meski Kota Batam sebagai salah satu kota industri di tanah air dan menjadi lokomotif pertumbuhan ekonomi nasional. Di sisi lain maraknya industri besar yang berdiri serta kehidupan masyarakat yang tidak peduli terhadap lingkungan sekitarnya menambah permasalahan yang ada saat ini. Mulailah tumbuh tumpukan sampah dan limbah yang merusak pemandangan lingkungan. Masalah ini berakibat pada kesehatan penduduk dan bencana banjir tidak dapat dihindari.

Pada prinsipnya untuk mencegah terjadinya pencemaran lingkungan, pemerintah Kota Batam telah melakukan pengawasan dan penegakan hukum. Kota Batam sendiri mempunyai Peraturan Daerah Kota Batam Nomor 8 Tahun 2003 Tentang Pengendalian Pecemaran dan Perusakan Lingkungan Hidup. Diberlakukannya peraturan tersebut membawa dampak positif terhadap pelaksanaan AMDAL di Kota Batam. Peraturan tersebut berlaku efektif ketika ada didukung oleh penegakan hukum lingkungan. Dengan demikian penegakan hukum lingkungan dilakukan oleh pemerintah yaitu institusi lingkungan hidup atau Badan Pengendalian Dampak Lingkungan Hidup Daerah (Bapedalda).

Dari data yang diperoleh dari Pemerintah Kota Batam Tentang Rencana Pembangunan Jangka Menengah Daerah RPJMD Kota Batam Tahun 2016, efektivitas Pemerintah Kota Batam dalam melaksanakan pemantauan pencemaran dan status mutu air mengalami trend yang cukup baik. Sepanjang tahun 2013-2015 Pemerintah Kota Batam telah melaksanakan pemantauan pencemaran dan status mutu air di seluruh kawasan pemukiman atau industri dan sumber mata air (Tabel 1.1). Sedangkan pada tahun 2011-2012, pemantauan hanya terlaksana sebanyak 80\% dari keseluruhan kawasan pemukiman atau industri dan sumber mata air. Hal ini menunjukkan adanya pengendalian terhadap pencemaran sumber air yang lebih baik dibandingkan dengan tahun 2011-2012 (Pemerintah Kota Batam, 2016: 100).

Persentase tingkat pengawasan pengendalian pencemaran limbah (\%) di Kota Batam pada periode 2011 hingga 2015 mengalami kenaikan tren (Tabel 1.1). Pada tahun 2012 hingga 2015 realisasinya berhasil melampaui target yang telah ditentukan dalam RPJMD 2011-2016, yaitu masing-masing sebesar $28 \%$, 46\%, dan $72 \%$. Terjadinya pencemaran lingkungan berpengaruh terhadap air tanah dangkal, sehingga pengawasan dan pengendalian pencemaran air limbah perlu ditingkatkan.

Tabel 1. Persentase Tingkat Pengawasan dan Pengendalian Pencemaran Limbah di Kota Batam

\begin{tabular}{|c|c|c|}
\hline Tahun & Target (\%) & Realisasi (\%) \\
\hline 2011 & 0 & 27 \\
\hline 2012 & 10 & 28 \\
\hline 2013 & 20 & 46 \\
\hline 2014 & 50 & 72 \\
\hline 2015 & 60 & 73 \\
\hline
\end{tabular}

Sumber: Dinas Bapedalda Kota Batam

Selain dari pengawasan dan pengendalian pencemaran limbah, pengawasan juga dilakukan terhadap pelaksanan AMDAL. Pengawasan dan pengendalian terhadap pelaksanaan AMDAL masih belum terlaksana $100 \%$ mengingat terbatasnya kemampuan SDM Pemerintah Kota Batam dalam melakukan pengawasan terhadap perusahaan wajib AMDAL. Cakupan pengawasan terhadap pelaksanaan AMDAL pada tahun 2015 hanya sebanyak 60\% dari seluruh perusahaan wajib AMDAL (Tabel 1.2). 
Kendati demikian, capaian tersebut mengalami peningkatan dari tahun 2011 yang hanya sebanyak 25\% dari seluruh perusahaan wajib AMDAL. Cakupan pengawasan terhadap pelaksanaan AMDAL di Kota Batam dapat dilihat dalam tabel berikut ini:

Tabel 2. Cakupan Pengawasan terhadap Pelaksanaan AMDAL di Kota Batam

\begin{tabular}{|c|c|}
\hline Tahun & $\begin{array}{c}\text { Cakupan Pengawasan Terhadap } \\
\text { Pelaksanaan AMDAL di Kota Batam (\%) }\end{array}$ \\
\hline 2011 & 25 \\
\hline 2012 & 35 \\
\hline 2013 & 40 \\
\hline 2014 & 50 \\
\hline 2015 & 60 \\
\hline
\end{tabular}

Sumber: Dinas Bapedalda Kota Batam

Adapun penegakan hukum lingkungan di Kota Batam pada periode 2011-2015 telah berhasil melampaui target yang ditetapkan dalam RPJMD Kota Batam periode 2011-2016 (Tabel 1.3) sampai pada tahun 2015, pencapaian kinerja penegakan hukum lingkungan telah mencapai 100\%. Hal ini bermakna Pemerintah Kota Batam mampu menyelesaikan kasus lingkungan yang terjadi.

Tabel 3. Persentase Penegakan Hukum Lingkungan di Kota Batam

\begin{tabular}{|c|c|c|}
\hline Tahun & Target (\%) & Realisasi (\%) \\
\hline 2011 & 90 & 91.57 \\
\hline 2012 & 90 & 96.91 \\
\hline 2013 & 90 & 96.3 \\
\hline 2014 & 90 & 96.05 \\
\hline 2015 & 100 & 100 \\
\hline
\end{tabular}

Sumber: Dinas Bapedalda Kota Batam

Berdasarkan data tersebut di atas maka diperlukan kajian yang lebih mendalam untuk mengetahui efektivitas peningkatan pelaksanaan persentase AMDAL (Analisis Mengenai Dampak Lingkungan di Kota Batam.

\section{METODE}

Penelitian ini menggunakan deskriptif kualitatif. Penelitian deskriptif kualitatif adalah salah satu metode untuk mendapatkan kebenaran dan tergolong sebagai penelitian ilmiah yang dibangun atas dasar teori-teori yang berkembang dari penelitian dan terkontrol atas dasar empirik. Dalam penelitian ini, peneliti berusaha memecahkan masalah dengan menggambarkan analisis efektivitas kebijakan dan program badan pengendalian dampak lingkungan daerah (bapedalda) Kota Batam terhadap peningkatan persentase pelaksanaan AMDAL

Teknik pengumpulan data di dalam penelitian ini diperoleh dengan teknik wawancara, observasi dan mengumpulkan data-data sekunder. Wawancara dilakukan dengan menggunakan pedoman wawancara yang sudah dipersiapkan sebelumnya sebagai panduan. Adapun bentuk wawancara yang akan dilakukan adalah wawancara mendalam (in-depth interview) dengan cara menggali secara mendalam informasi dan data yang diperoleh dari informasi penelitian. Data dan informasi yang diperoleh dari informan akan direkam dan disimpan, setelah itu dibuatkan transkripnya agar memudahkan peneliti dalam melakukan analisis. Selain itu, data juga diperoleh dengan cara mengamati fenomena-fenomena di lapangan yang berhubungan dengan analisis efektivitas kebijakan dan program badan pengendalian dampak lingkungan daerah (bapedalda) Kota Batam terhadap peningkatan persentase pelaksanaan 
AMDAL. Teknik dokumentasi untuk mengumpulkan data-data sekunder yang berhubungan dengan objek penelitian.

\section{HASIL DAN PEMBAHASAN}

\section{a. Efektivitas Pelaksanaan Tata Lingkungan, Pengawasan, dan Penindakan AMDAL di Kota Batam}

Dinas Lingkungan Hidup Kota Batam yang meliputi Bidang Tata Lingkungan mempunyai tugas tentang tata lingkungan, pengawasan, penindakan dan bidang perlindungan lingkungan hidup. Dari data yang peneliti temukan di Database APDL Bapedal Kota Batam tahun 2016 mengambarkan bahwa AMDAL di Kota Batam semenjak dari tahun 2011 sampai dengan tahun 2016 mengalami fluktuasi dokumen. Tetapi secara keseluruhan dokumen-dokumen tersebut mulai dari AMDAL, UKL/UPL, DLPH, DELH dan SPPL mengalami kenaikan yang cukup siginifikan. Gambaran tersebut dapat dilihat dari tabel di bawah ini:

Dokumen Lingkungan Tahun 2016

\begin{tabular}{|c|c|c|c|c|c|c|}
\hline No. & Tahun & AMDAL & UKL/UPL & DPLH & DELH & SPPL \\
\hline 1. & 2011 & 10 & 168 & 50 & & 456 \\
\hline 2. & 2012 & 9 & 179 & - & & 292 \\
\hline 3. & 2013 & 11 & 192 & - & & 320 \\
\hline 4. & 2014 & 6 & 244 & 7 & 2 & 612 \\
\hline 5. & 2015 & 13 & 234 & 10 & 3 & 960 \\
\hline 6. & 2016 & 25 & 226 & - & - & 645 \\
\hline \multicolumn{7}{|c|}{ Jumlah } \\
\hline
\end{tabular}

Sumber: Database Bidang APDL Bapedal Kota Batam, 2016

Menurut UU Nomor 32 Tahun 2009 tentang perlindungan pengelolaan dan lingkungan hidup, upaya perlindungan dan pemantauan lingkungan hidup ini paling tidak ada 6 poin yang disebut dengan Rencana Perlindungan dan Pengelolaan Lingkungan Hidup (RPPLH). Dokumen RPPLH itu sendiri ialah perencanaan tertulis yang memuat potensi, masalah lingkungan hidup, serta upaya perlindungan dan pengelolaanya dalam kurun waktu tertentu.

Dari 6 poin di RPPLH tersebut adalah perencanaan, pemanfaatan, pengendalian, pemeliharaan, pengawasan dan penindakan hukum. Pada poin perencanaan dan pemanfaatan tidak menyentuh pada poin AMDAL. Nanti dalam proses pengendalian itu terbagi atas beberapa segmen, mulai dari pencegahan, penanggulangan dan pemulihan. Uraian dari penjelasannya adalah sebagai berikut:

\section{Aspek Pencegahan dan Pengawasan Lingkungan Kawasan Industri Kota Batam Di lihat Dari Prepsektif Kajian AMDAL}

AMDAL ini merupakan salah satu instrumen untuk pencegahan terjadinya pencemaran dan kerusakan lingkungan hidup. Instrumen lainnya banyak seperti KLHS, pengaturan tata ruang dan perizinan.

AMDAL adalah alat ukur untuk pencegahan awal terhadap potensi pencemaran dan kerusakan lingkungan. Instrumen lain ada, termasuk analisis resiko ada UKPL, AMDAL dan KLHS. Kota Batam sendiri untuk pencegahan agar tidak terjadi kerusakan lingkungan akibat dari proyek industri besar, kajian AMDAL berfungsi terhadap dampak pencegahannya. Kota Batam sebagai kota industri sebelum membuat usaha menghasilkan limbah yang membawa dampak kepada lingkungan sudah ada studi perencanaanya, Kota Batam ini sudah ada penzoningan kawasan industri, misalnya kawasan industri 
muka kuning, panbil, kabil, tunas, semua dalam satu area itu sudah diperhitungkan, sudah ada kelayakan untuk studi AMDAL-nya."

Untuk kawasan industri terpadu studinya sudah ada, dan pengelolaan limbahnya juga sudah jelas, mulai dari penyelesaiannya sampai pengelolaannya sendiri. Untuk material yang harus dikirim karena mengandung B3 mereka sudah ada langsung bekerja sama dengan pengusaha. Di Kota Batam yang paling besar itu adadah PT Desa Air Kargo. Limbah tersebut harus dibawa keluar karena di Kota Batam tidak ada pengelolaannya. Lokasi pengelolaanya berada di Cibinong. Kemudian untuk sampah-sampah elektronik, kalau dia disinyalir mengandung limbah B3 maka dia harus dikirim ke Cibinong. Kalau dia sampah baru dikirm ke Tempat Akhir Pembuangan Sampah (TPA) di daerah Punggur. Dampak Kota Batam sebagai kota industri jelas menghasilkan sisa-sisa produksi. Peran AMDAL di Batam sendiri kemudian cukup efektif dalam hal proteksi kawasan lingkungan agar tidak tercemar dari B3.

"Khusus AMDAL kawasan industri Batamindo, kebutuhan airnya $10.000 \mathrm{~m} 2$ per/hari, kawasannya kurang lebih 300 hektar itu. Kebutuhan air di kawasan Batamindo itu sebanyak 8 kali Hotel Aston. AMDAL berfungsi bagaimana cara mengendalilkannya agar tidak terjadi pencemaran lingkungan. Semuanya dikaji dalam AMDAL, air limbah 10.000 ini menjadi beban bagi lingkungan kalau tidak dikelola. Mampu mengelola dari segi kualitas dan kuantitas. Kualitasnya harus memenuhi paku mutu, volume terlayani. Jika tidak memenihi syarat maka akan di tolak AMDAL nya."

Khusus untuk pencegahan, AMDAL memainkan peranan penting agar kawasan industri di Kota Batam betul-betul mengkaji aspek pencemaran dan kerusakan lingkungan di sekitarnya. Memadai atau tidaknya industri tersebut perlu lagi dilihat dokumen AMDALnya. Dengan demikian AMDAL dilihat dari aspek pencegahan adalah dari studi kelayakan atau tidaknya dari sebuah proyek industri yang akan dan sedang dibangun.

Di Dinas Lingkungan Hidup sendiri memiliki mekanisme pengawasan. Misalnya: Apabila sebuah hotel dalam mekanisme pembuatannya sudah benar, namun saat dibangun IPAL, ternyata buangan jelek dan berbau, yang dilakukan DLH dalam bentuk mekanisme pengawasan adalah sebagai berikut: (1) Pengawasan izin lingkungan, (2) Pengawasan izin limbah cair, (3) Pengawasan TPS limbah B3. Ke tiga aspek tersebut merupakan bentuk pengawasan dari Dinas Lingkungan Hidup Kota Batam, agar dari segi lingkungan, limbah cair dan limbah B3 dapat diminimalisir dampak pencemaran dan kerusakan lingkungannya. Semua itu merupakan bentuk pengawasan dalam peningkatan AMDAL di Kota Batam.

Dapat ditarik kesimpulan bahwa dari aspek pencegahan dan pengawasan AMDAL di Kota Batam, memiliki aspek yang diperhatikan, sebab semua dikaji dalam AMDAL. Dampak fisik yaitu: limbah, sampah, air, tanah, udara. Tidak boleh sembarang bangun cerobong, kapan harus diuji tes, bagaimana tidak mengganggu lingkungan, dan seberapa banyak teknologi yang dipakai.

Secara statistik tingkat kepatuhan industri di Kota Batam ini paling tinggi di Indonesia, 3 hal ini dilakukan adalah kesadaran, sosialisasi dan law enforcement (Penegakan hukum). Sampai saat ini penegakan hukum merupakan bentuk terakhir dari RPPLH agar penceagahan dan pengawasan lingkungan itu efektif dilakukan oleh Bapedalda Kota Batam.

\section{Aspek Pengendalian AMDAL Di Kota Batam}

Pengendalian ini adalah tahap awal sebelum dilakukan kegiatan operasional, disitu dikaji mulai dari buka lahan, melakukan pematangan lahan dan menata drainasenya, menata officenya sampai prosesnya, ini kadang-kadang terlupakan. Jadi bisa dikatakan ketika perusahan melakukan pelanggaran AMDAL patut dicurigai mereka tidak peduli dan komitmen terhadap menjaga lingkungan."

Perusahaan di Batam ini cuma 3 yang mendapatkan sertifikat RPJP, dan yang menilai itu ada komisi penilaian AMDAL. Komisi penilaian AMDAL tersebut ada tim teknis yang berjumlah 14 ahli. Tim teknis tersebut ada yang berlatang belakang teknik kimia, sipil, tata ruang, ahli lingkungan kemudian ahli pengairannya. Komisi penilai terebut yang menilai apakah dokumennya layak atau tidak. Ketika tim 
teknis mengatakan dokumen tersebut layak lalu diteruskan ke penilaian AMDALnya. Kemudian masuk ke komisi pusat yang jumlah nya 35 orang, waktu SOP berlangsung selama 105 hari di komisi.

Waktu penilaian AMDAL bisa 5 sampai 6 bulan lamanya, setelah layak lalu komisi memberikan rekomendasi kepada wali kota. Kemudian baru wali kota menerbitkan SKL, (Surat Kelayakan Lingkungan), setelah itu baru yang bersangkutan keluar izin lingkungan. Paling tidak terdapat 3 poin dalam peningkatan persentase AMDAL yaitu :

1. Peningkatan kebutuhan investor dalam bentuk voluntery dari perusahaan

2. Usaha kita dalam konteks sosialisasi, pembinaan dalam bentuk dor to dor

3. Penyadaran publik dengan melakukan law enforcement dalam bentuk upaya yang terakhir

\section{Aspek Sanksi Pelanggaran AMDAL Di Kota Batam}

Aspek sanksi pelangaran AMDAL di Kota Batam adalah sebagai upaya agar industri di Kota Batam patuh dan taat terhadap aturan. Sanksi yang diberikan cukup tegas terhadap pelanggaran AMDAL. Dari hasil penelitian ditemukan:

Dari 100 daerah industri terdapat 10 tidak memiliki dokumen, dan nanti dari 10 itu dilihat lagi, yang paling urut dari 10 siapa yang melanggar AMDAL. Agar yang lainnya mendapatkan efek jera dapat dipidanakan dengan sanksi kurungan penjara. Pasal 109 dilanggar tidak memiliki izin lingkungan saja pidananya itu sampai 1 sampai 3 tahun. Satu izin yang memiliki aspek pidana adalah izin lingkungan. Izin lingkungan jika tidak ada AMDAL itu sanksinya berat. Dasar hukumnya jelas diatur dalam undangundang.

Berikut dijelaskan bunyi pasal 109 Undang-Undang Nomor 32 Tahun 2009 Tentang Perlindungan dan Pengelolaan Lingkungan Hidup "setiap orang yang melakukan usaha dan/atau kegiatan tanpa memiliki izin lingkungan sebagaimana dimaksud dalam pasal 36 ayat (1) dipidana dengan pidana penjara paling singkat 1 (satu) tahun dan paling lama 3 (tiga) tahun dan denda paling sedikit Rp.1000.000.000,00 (satu miliar rupiah) dan paling banyak Rp 3.000.000.000,00 (tiga miliar rupiah).

jenis pelanggaran terdapat 2 macam yakni:

1. Pelanggaran dalam operasional kegiatan, pelanggaran saat melakukan kegiatan tampa AMDAL atau pelanggaran mereka sudah punya AMDAL tetapi tidak mengikuti petunjuk AMDAL.

2. Ada yang sudah running tapi tidak punya AMDAL sama sekali. Pada akhirnya limbahnya dibuang kemana-mana karena tidak punya AMDAL.

\section{b. Faktor Yang Mempengaruhi Peningkatan Persentase AMDAL di Kota Batam}

1. Sikap optimis dari pengusaha membuat permohonan dokumen AMDAL meningkat

Pertumbuhan peningkatan dokumen lingkungan tersebut dilihat dari semangat investor melakukan investasi. Kota Batam ini sekarang memiliki kurang lebih 1.200 industri dengan luasnya kurang lebih 400 km2. Jadi proteksi sangat dibutuhkan agat persentase AMDAL dapat terus meningkat. Dibandingkan dengan Pulau Jawa dan Sumatera, Kota Batam memiliki daya dukung kecil. Pulau Jawa dan Sumatera daratannya sangat luas, yang luasnya bisa ribuan kilo $\mathrm{m} 2$ bahkan bisa puluhan ribu. Pulau Jawa dan Sumatera mempunyai daya dukung yang luar biasa. Walaupun keadaanya demikian, Kota Batam terus meningkatkan persentase AMDAL. Yang lagi "running" sekarang itu ada di proyek Habibie, Oksler dan proyek Harbour Bay Batam, semua itu ada memiliki 20 dokumen AMDAL.

2. Konsultan lingkungan Kota Batam Yang Qualified

Dari paparan Ketua Bidang Lingkungan Kota Batam memang tidak mudah mencari konsultan lingkungan yang "qualified" atau menguasai terhadap lingkungan. Mekanismenya cukup panjang untuk merekrut tim ahli konsultan lingkungan tersebut. Verikasinya itu tidak mudah. Tim penyusun AMDAL Kota Batam berasal dari ITB, IPB, UI dan lain sebagainya. Mereka merupakan tim ahli yang akan merumuskan kajian AMDAL untuk menguji studi kelayakan atau tidaknya sebuah proyek industi dan 
usaha. Konsultan yang mumpuni dan ahli dibidangnya sangat mempengaruhi terhadap peningkatan persentase AMDAL di Kota Batam.

3. Tim Teknis dan Komite Penilaian AMDAL Kota Batam Memiliki Pengetahuan Luas Dalam melaksanakan tugasnya komisi penilai AMDAL Kota Batam dibantu oleh tim teknis yang terdiri atas pakar independen. Pakar independen dan sekretariat sebagaimana dimaksud pada ayat (3) UU 32 Tahun 2009 ditetapkan oleh Menteri, Gubernur atau Bupati/Walikota sesuai dengan kewenangannya. Penguasaan mereka terhadap analisis mengenai dampak lingkungan akan berpengaruh terhadap pencemaran dan kerusakan lingkungan. Apalagi AMDAL ini merupakan kajian dalam skala besar dalam upaya proteksi pencemaran dan kerusakan lingkungan di Kota Batam.

\section{KESIMPULAN}

Efektivitas kebijakan dan program Bapedalda Kota Batam terhadap peningkatan persentase pelakanaan AMDAL dapat simpulkan sebagai berikut:

1. Bapedalda Kota Batam tahun 2016 menggambarkan bahwa AMDAL di Kota Batam semenjak dari tahun 2011 sampai dengan tahun 2016 mengalami fluktuasi dokumen. Tetapi secara keseluruhan dokumen-dokumen tersebut mulai dari AMDAL, UKL/UPL, DLPH, DELH dan SPPL mengalami kenaikan yang cukup siginifikan.

2. Efektifitas AMDAL di Kota Batam untuk kawasan industri yang berskala besar seperti Batamindo, Kabil, Panbil sudah efektif dalam pelaksanaan AMDALnya. hanya saja untuk kawasan daerah pantai memang masih belum efektif sebab masih ditemukan kurangnya kesadaran dan sifat-sifat nakal oleh pengelola perusahaan (investor).

3. Agar efektivitas tersebut dapat dilakukan maka pelaksanaan RPPLH dilakukan Oleh Bapedal yakni mulai dari perencanaan, pemanfaatan, pengendalian, pemeliharaan, pengawasan dan penidakan hukum

4. Bentuk pengawasan yang dilakukan dalam bentuk pengawasan izin lingkungan, pengawasan izin limbah cair dan pengawasan TPS limbah B3. Ke tiga bentuk pengawasan tersebut dilakukan dari Dinas Lingkungan Hidup Kota Batam, bagian Tata Lingkungan.

5. Terdapat 3 poin dalam peningkatan persentase AMDAL yaitu: (1) peningkatan kebutuhan investor dalam bentuk voulunter (Sukarelawan) dari perusahaan, (2) Usaha kita dalam konteks sosialisasi, pembinaan dalam bentuk dor to dor, (3) Penyadaran publik dengan melakukan law enforcement (Penegakan Hukum) dalam bentuk upaya yang terakhir.

6. Adapun faktor yang mempengaruhi peningkatan persentase AMDAL di Kota Batam (1) Sikap optimis dari pengusaha membuat permohonan dokumen AMDAL meningkat, (2) Konsultan lingkungan Kota Batam yang qualified, (3) Tim Teknis dan komite penilaian AMDAL Kota Batam memiliki pengetahuan luas.

7. Masalah Peningkatan persetase AMDAL di Kota Batam ialah: (1) Kota Batam masih kurang kreatif bila dibanding dengan di daerah-daerah lain, sebab daerah seperti Kota Balik Papan pengelolaan lingkungannya sudah memiliki nilai tambah, (2) Masalah di Kota Batam secara geografis dikelilingi oleh laut jadi materianya terbatas karena hanya manfaatkan dari potensi laut seperti pasir, sedangkan di satu sisi abrasi merupakan dampak kerusakan lingkungan laut, (3) Investor di Kota Batam ada yang tidak melaporkan neraca limbahnya. (5) Kota Batam belum mempunyai infrastruktur, contoh: laboratorium. 


\section{SARAN}

1. Hasil dari analisis mengenai dampak lingkungan (AMDAL) seyogyanya dapat memperhatikan aspek perlindungan lingkungan secara menyeluruh, khususnya ekosistem laut agar tidak tercemar dengan limbah industri.

2. Pemerintah Kota harus mampu mengakomodasi kepentingan dan kebutuhan masyarakat misalnya kebijakan dan program yang mampu memberikan nilai tambah secara ekonomi buat masyarakat.

3. Pemerintah Kota Batam harus melakukan inovasi agar keterbatasan sumber daya dapat diatasi, karena seperti yang diketahui Kota Batam sangat terbatas dari sumber daya yang hanya di kelilingi oleh laut.

\section{DAFTAR PUSTAKA}

[1]. Abidin, Z. S. (2012). Kebijakan Publik. Jakarta: Salemba Humanika.

[2]. Agustino, L. (2008). Dasar-Dasar Kebijakan Publik. Bandung: Alfabeta.

[3]. Arafat Akkar. (2010). Pengalihan Status Free Trade Zone (FTZ) Menjadi Special Economic Zone (SEZ) Dalam Hubungan Kerjsasama EKonomi Indonesia dan Singapura Contoh: Kasus Batam Periode 2007-2010. Jakarta: FISIP UI.

[4]. Aryadana, D. A. (2014). Peran Badan Pengendalian Dampak Lingkungan Daerah Dalam Pengendalian Pencemaran Terhadap Kegiatan Industri Di Kota Batam Tahun 2011-2014. JOM FISIP, 2(2).

[5]. Aung, T. S. (2017). Evaluation Of The Environmental Impact Assessment System And Implementation in Myanmar: Its Significance in Oil and Gas Industri. Enviromental Impact Assessment Review, 66, 24-32.

[6]. Goesty, P. A., Samekto, A., \& Dwi P Sasongko. (2012). Analisis Penataan Pemrakarsa Kegiatan Bidang Kesehatan di Kota Magelang Terhadap Pengelolaan Dan Pemantauan Lingkungan Hidup. Ilmu Lingkungan, 10(2), 89-94.

[7]. Islami, I. (2014). Kebikan Publik. Tangerang Selatan: Universitas Terbuka.

[8]. Makela, M. (2017). Envirolmental Impact and Aspects in the forest Industri: What kind of picture do corporate environmental reports Provide. Forest Policy And Economics, 80(1), 178-191.

[9]. Mutiarin, D., \& Arif Zaenudin. (2014). Manajemen Birokrasi dan Kebijakan Penelusuran Konsep Dan Teori. Yogyakarta: Pustaka Pelajar.

[10].Pemerintah Kota Batam. (2016). Peraturan Daerah Kota Batam Nomor 8 Tahun 2016 Tentang Rencana Pembangunan Jangka Menengah Daerah (RPJMD) Kota Batam Tahun 2016-2021.

[11].Pertiwi, D. U., Edy, A., \& Eko Yudiatmaja, W. E. (2014). Pengaruh Kemampuan Kerja Terhadap Efektivitas Organisasi Pada Dinas Kebudayaan Provinsi Kepulauan Riau. JUAN, 2(1), 56. 
[12].Purwanti Anggel. (2016). Penataan Objek Wisata Sebagi Strategi Komunikasi Dinas Pariwisata Dan Kebudayaan Visit Batam 2010. Komunikasi, 10(1), 29-40.

[13].Purwanti, L., \& Lukito, Y. R. D. (2014). Pengaruh City Branding Kota Batam Terhadap Brand Attitude. Manajemen, 14(1), 61-80.

[14].Sari, T. F. P., Makmur, M., \& Rozikin, M. (2016). Eefektivitas Implementasi UKL-UPL Dalam Mengurangi Kerusakan Lingkungan (Studi pada Badan Lingkungan Hidup Kabupaten Malang dan Masyarakat Sekitar PT Tri Surya Plastik Kecamatan Lawang). Adminisstrasi Publik (JAP), Fakultas Ilmu Administrasi, Universitas Brawijaya, Malang, 2(1), 161-168.

[15].Sentosa, A. R., \& Rochana, E. (2014). Efektifitas sosialisasi kebijakan pemerintah Kota Bandar Lampung Waktu Pembuangan Sampah Sebagai Upaya Menciptakan Kebersihan Lingkungan. Sosiologi, 14(1), 1-9.

[16].Sjafrizal. (2015). Perencanaan Pembangunan Daerah Dalam Era Otonomi. Jakarta: PT Raja Grafindo Persada.

[17]. Sugiono. (2012). Metode Penelitian Kuantitatif Kualitatif Dan $R \&$ D. Bandung: Alfabeta.

[18].---------. (2014). Metode Penelitian Kuantitatif, Kualitatif, Dan R\&D. Edisi Kedua puluh satu. Bandung: Alfabeta.

[19]. Wahyono, Suntoro, \& Sutarno. (2012). Efektivitas Pelaksanaan Dokumen Lingjungan Dalam Perlindungan Dan Pengelolaan Lingkungan Hidup Di Kabupaten Pacitan Tahun 2012. Ekosains, IV(2), 43-52.s 